\title{
A HIERARCHICAL APPROACH FOR DEFINING AND CLASSIFYING CONSTRUCTS IN MANAGEMENT AND MARKETING RESEARCH: EXAMPLES FROM THE FIELD OF DYSFUNCTIONAL BEHAVIOR
}

\author{
DOI: 10.17261/Pressacademia.2018.807 \\ JMML- V.5-ISS.1-2018(5)-p.55-65 \\ Mehmet Okan ${ }^{1}$, A. Banu Elmadag ${ }^{2}$ \\ ${ }^{1}$ Istanbul Technical University, Istanbul, Turkey. \\ mokan@itu.edu.tr, ORCID: 0000-0002-9303-5768 \\ ${ }^{2}$ Istanbul Technical University, Istanbul, Turkey. \\ elmadaga@itu.edu.tr,ORCID: 0000-0002-3611-3977
}

\section{To cite this document}

Okan, M., Elmadag, A. B., (2018). A hierarchical approach for defining and classifying constructs in management and marketing research: examples from the field of dysfunctional behavior. Journal of Management, Marketing and Logistics (JMML), V.5(1), p.55-65.

Permemant link to this document: http://doi.org/10.17261/Pressacademia.2018.807

Copyright: Published by PressAcademia and limited licensed re-use rights only.

\begin{abstract}
Purpose - Construct clarity and overlapping problems are obvious in management and marketing literatures. Moreover, they cause serious methodological problems. It is vital to provide meaningful definition and classification procedures for management and marketing phenomena. Current paper argues that defining and classifying constructs using hierarchical approach can provide clear and practically meaningful construct definitions and classifications.

Methodology - Current paper reviews construct definition articles in the fields of management, marketing and psychology in order to provide hierarchical construct definition and classification procedure. Authors also apply this procedure in the field of dysfunctional behavior, which has seriously suffered from construct definition overlaps.

Findings- Although previous literature tends to classify constructs dichotomously (latent constructs and observable variables), our literature review discovers more than two levels in the hierarchical abstraction-generalizability continuum, such as umbrella and bridging constructs.

Conclusion- Current paper concludes that using hierarchical criteria map for defining and classifying constructs may cause meaningful, distinct (but not disconnected) construct definitions, which clearly target real world phenomena.
\end{abstract}

Keywords: Construct definition, dysfunctional behavior, construct clarity, umbrella constructs, bridging constructs JEL Codes: M00, D23, D90

\section{INTRODUCTION}

Development of meaningful theory in the fields of management, marketing and other behavioral sciences need precision and clarity in conceptualization (DiRenzo, 1966; Podsakoff, Mackenzie, and Podsakoff, 2016). One major challenge in management and marketing research is providing construct clarity (Suddaby, 2010) because several study fields in these literatures suffer from meaningless and overlapping construct proliferation. Also, several frequently used constructs have overlapping problems, such as counterproductive work behavior, employee burnout and engagement, and customer satisfaction. Moreover, recent studies show that conceptual differences between these constructs are not supported by field data. For instance, independence of the dimensions of job burnout from employee (dis)engagement is generally accepted. However, Cole, Walter, Bedeian and O'Boyle's (2012) meta-analytic confirmatory factor analysis show that subconstructs of engagement (vigor, dedication and absorption) are better explained by burnout than engagement. One of the sub-constructs of burnout (personal inefficacy), more strongly correlates with engagement constructs, than other burnout constructs (exhaustion and cynicism). Another example is from the field of interpersonal and organizational mistreatment in workplaces. According to several well-established scholars, popular mistreatment constructs, with a few distinctive characteristics, have considerable overlapping definitions and measurement methods (Aquino and Thau, 2009; Hershcovis, 2011; Shapiro, Duffy, Kim, Lean, and O'Leary-Kelly, 2008). Meta-analytic study of Hershcovis (2011) also finds no considerable differences between the effects of different interpersonal mistreatment constructs (such as aggression, 
incivility, social undermining and interpersonal conflict) on job outcomes (job satisfaction, turnover intent, affective commitment, and well-being). Therefore, several study fields have obviously suffered from construct clarity and overlapping problems and these problems cause serious methodological problems. Thus, it is vital to provide meaningful definition and classification procedures for management and marketing phenomena. The current paper argues that hierarchically defining and classifying constructs can provide clear and practically meaningful construct definitions and classifications.

With the purpose of developing protocol for construct classification, an extensive review of construct development and clarification studies in management and marketing literature is carried out (Bacharach, 1989; Bagozzi and Edwards, 1998; Churchill and Jr., 1979; Edwards and Bagozzi, 2000; Floyd, Cornelissen, Wright, and Delios, 2011; Gilliam and Voss, 2013; Hirsch and Levin, 1999; Jarvis, MacKenzie, and Podsakoff, 2003; Locke, 2012; MacKenzie, 2003; Mowen and Voss, 2008; Podsakoff et al., 2016; Rossiter, 2011; Suddaby, 2010). In this paper, based on the aforementioned review, main issues and contradictory arguments are discussed. Then, previous construct definition and classification arguments are synthesized and criteria map is suggested.

\section{CONCEPTS AND CONSTRUCTS: IMPORTANCE OF CONSTRUCT CLARITY FOR BEHAVIORAL SCIENCES}

Although prominence of the good conceptualization has been discussed since John Stuart Mill, problem of the inadequate concept and construct definitions still create crucial problems for social scientists, especially for management and marketing researchers (Podsakoff et al., 2016; Suddaby, 2010). Moreover, social scientists still have not arrived at a consensus on the definitions of "concept" and "construct" and the differences between them. There is a variety of definitions and meanings of the term "concept", for the purposes of this study, we prefer to use the definition of Podsakoff et al., (2016, p. 3);

\footnotetext{
"cognitive symbols (or abstract terms) that specify the features, attributes, or characteristics of the phenomenon in the real or phenomenological world that they are meant to represent and that distinguish them from other related phenomena. Thus, a concept is a cognitive symbol that has meaning for the scientific community that uses it."
}

There are two main reasons for preferring this definition: (1) This definition stresses the importance of distinguishing characteristics of concepts. Therefore, according to this perspective, discovering, defining and labeling a phenomenon are not enough for good conceptualization and clear construct definition (Gilliam and Voss, 2013; Goertz, 2006). Construct and concepts are distinct cognitive symbols in nature. (2) Contrary to the realist view (Bagozzi, 2007), Podsakoff et al., (2016) argue, concepts are not only the reflections of real world, but also phenomenological world phenomena so it can be argued that concepts are not strictly dependent on the actual empirical world. At this stage, Markus (2008) differentiates concepts from constructs although they are sometimes used interchangeably in literature. Bacharach (1989) defines constructs as approximated, but not directly observable, units of broad mental configurations or abstractions in an empirical world. According to Markus (2008), while constructs are highly dependent on actual conditions (population), concepts are abstractions can exist free from the actual conditions concepts. For instance, as previously explained, today, it cannot be easily argued that burnout and engagement are totally distinct constructs because previous studies find that dimensions of these constructs are highly correlated (Cole et al., 2012). Thus, revision for the construct definitions of burnout and engagement is needed. However, according to Markus (2008), we can still argue that burnout and engagement are conceptually different. We can rationally differentiate them and it is possible to confirm differences of these concepts in the future. Therefore, in this paper, it is assumed that concepts are hypothetical constructs (Podsakoff et al., 2016) but constructs are highly dependent on the actual empirical world.

Concepts or constructs are indispensable tools for scientific explanations (DiRenzo, 1966). According to Gerring (2008), concepts and constructs address the most basic scientific question in every social science: "What are we talking about?". Well-employed construct definitions need clarity that provides comprehensible, distinct and robust categories of observations related to phenomena (Suddaby, 2010). Moreover, according to Suddaby (2010), construct clarity involves (1) well-employed definitions that include precise distinction between concepts, (2) boundary conditions that elaboration of the context which a construct can be applied to or not applied to, (3) well-explained semantic relationships with other related constructs (4) logical consistency with overall theoretical argument. Locke (2012), on the other side, argues construct clarity should be supported by conceptual clarity, which additionally needs (5) logically valid conceptual definitions, (6) strict connection between concepts and their scales, (7) logical connection between constructs and subcontracts.

Based on these views, it can be argued that good constructs need to be distinct (but not disconnected), delimited, related (with overall theories of the field and actual conditions (reality) as well as with other constructs in the field). It is necessary that constructs should be positioned in the conceptual map in order to provide clarified hierarchical and horizontal position 
in their study fields. Hierarchical position (or abstraction level) of constructs reflects their distance with empirical area (variables) and their scope. Horizontal position, on the other hand, determines their dimensional differences and relations with other constructs in the same hierarchical level.

\section{HIERARCHICAL CRITERIA MAP FOR CONSTRUCT CLARITY}

Several studies on construct definition argue that there has to be distinction between constructs, concepts and variables (or expressions) based on their abstraction levels (Bacharach, 1989; Bagozzi, 2007; Osigweh, 1989; Podsakoff et al., 2016). For instance, Bacharach (1989) makes distinction between constructs and variables and states that constructs are more abstract and more generalizable than variables. He also argues that, certain constructs are specific, rich in detail but strictly bound to the empirical findings, while others are highly abstract level grand theoretical statements but lack in observational details. Osigweh (1989) argues there are two types of constructs based on their abstraction levels: universal (or theoretical) constructs and observational (or empirical) constructs. Universal constructs are totally abstract constructs that represent a large class of subconstructs and their connection to empirical world can be weak. Empirical constructs, on the other hand, are both abstract and concrete and they can be used in abstract definitions of phenomena and/or direct observations. Empirical constructs also consist of a level of abstraction but they have high ability to be more abstract or more concrete. According to Hirsch and Levin (1999), this distinction is rooted in the tendencies of scholars. They argue that, in literature, there are two groups with opposite tendencies for construct development: umbrella advocates and validity polices. First group, umbrella advocates, see broad patterns and synthesize regularities into integrative broadly defined constructs, namely umbrella constructs. Second, validity polices, see a lot of narrowly defined problems and issues, namely specific constructs, and challenge with inconsistencies within the umbrella constructs. According to Hirsch and Levin (1999), tension and challenge with umbrella advocates and validity polices initiate healthy construct lifecycle processes because this tension is eased with new typological explanations. It can be argued that ease of tension process between highly abstract and highly concrete constructs cause more healthy and valid intermediate forms of constructs, such as umbrella constructs, bridging constructs. In this paper, it is argued that abstraction level is critical since classifying and defining constructs in only two levels may not be enough to fulfill the needs of highly prolific and complex study fields in management and marketing literature.

Constructs need to be ordered and arranged based on their abstraction levels (Mowen and Voss, 2008). In this study, based on the literature review on construct definition studies in management, marketing and psychology in general, six hierarchical construct levels based on the abstraction level and generality of the construct are defined: General terms, umbrella constructs, bridging constructs, specific constructs, general expressions and behavioral expressions (see Figure 1). Authors develop and suggest a hierarchical model for organizing constructs within the fields of organizational and marketing research.

As visualized in Figure 1, authors argue that well-employed constructs should be positioned between the upper and lower thresholds of abstraction or generalization. As previously discussed, scholars argue that constructs are related to the real or phenomenological world phenomena and a construct definition should congruently reflect its phenomenon. However, in marketing and management literatures, there are several highly abstract and amorphous conceptualizations that include a bunch of weakly related behaviors, which cannot reflect a phenomenon. On the other hand, there are also several behavioral expressions in organizations or in markets, which cannot constitute a phenomenon on their own. Rather, these expressions can only be a manifestation of a phenomenon in the real world, not the conceptualization of it. 


\section{Figure 1: Criteria Map for Hierarchical Classification of Constructs}

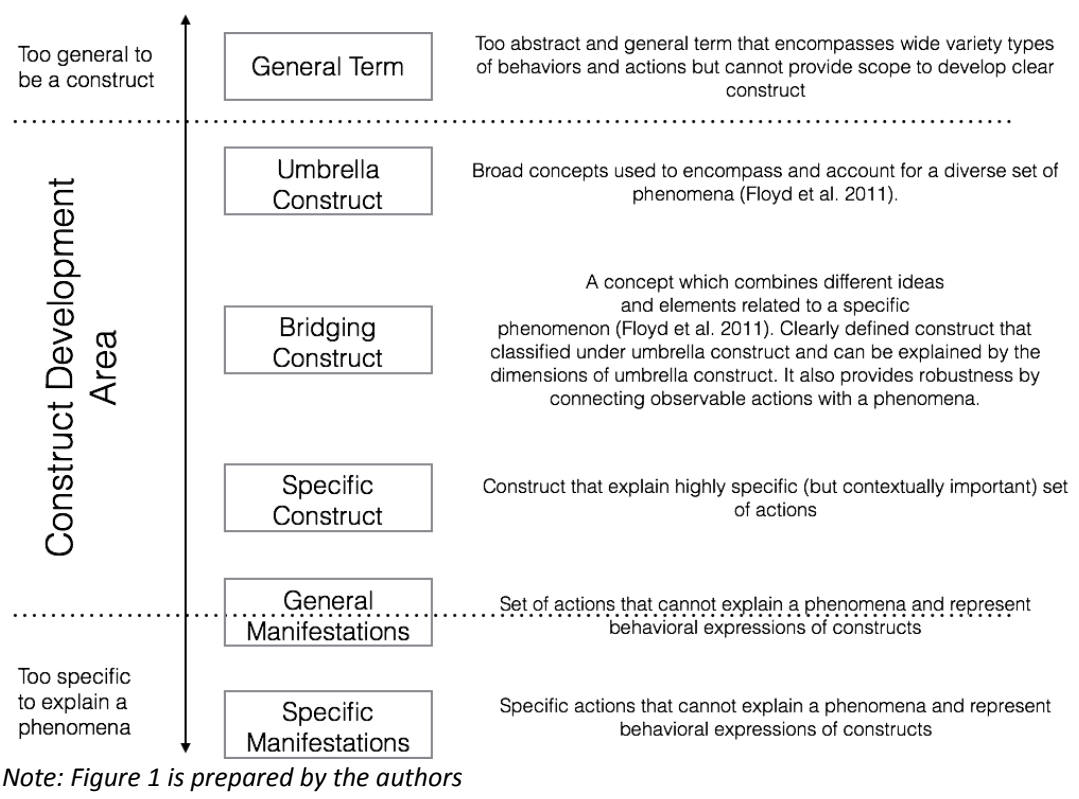

\subsection{General Terms}

Defining constructs too broad cause vague and meaningless terminology, which may embrace weakly related various constructs together. Too broad and unlimited definitions fail to target and explain a phenomenon. According to Locke (2012), several scholars believe concepts are subjective notions and one of the consequences of this belief is lumping unrelated constructs together. We use 'general terms' that indicate highly abstract labels and definitions that encompass wide variety of weakly related concepts that may not have substantive elements in common. Locke (2012) argues that these types of conceptualizations damage the meaning and value of the phenomena. It is obvious that using general terms cause researchers to miss some interesting, distinct and meaningful attributes and characteristics of concepts (Tepper and Henle, 2011). It is almost impossible to develop valid operational definitions for these terms directly. These are highly vague explanations and hard to connect operational areas. However, we argue that these types of broad terms are useful to indicate a study field. For instance, today, "organizational frontlines" is one of the most popular terms in marketing and service research. It identifies the "interactions and interfaces at the point of contact between an organization and its customers that promote, facilitate, or enable value creation and exchange" (Singh, Brady, Arnold, and Brown, 2017, p. 4). This term captures a wide variety of distinct service components (such as physical, digital, procedural) and actors (such as customers, frontline employees, managers, IT department) that can hardly be unified in a concept. However, as Singh et al. (2017) explained, it indicates a study field, rather than a concept, that tries to understand the intersection between customer-organization interactions and interfaces. We argue that these types of well-defined general terms clarify the subject matter and promotes systematized body of knowledge (Hunt, 1976) thus we believe that determining the 'general term' is the first step for answering the question of "What are we talking about?".

\subsection{Umbrella Constructs}

Different constructs can be grouped together under a single, explanatory label but they need elements in common. Although, umbrella constructs sometimes have negative connotations in the literature, we use it as a level for constructs that integrate diverse but interrelated group of concepts. Umbrella constructs are broad concepts used to encompass and account for a diverse set of phenomena (Hirsch and Levin, 1999). Umbrella constructs are broad in scope, encompass multiple ideas and they have broad interpretive framework (Floyd et al., 2011). Although they provide common elements for interrelated phenomena (Locke, 2012), umbrella constructs barely provide dimensional explanations. Constructs such as dysfunctional customer behavior (Harris and Reynolds, 2003; Reynolds and Harris, 2009) or consumer misbehavior (Fullerton and Punj, 2004) are broadly defined constructs that encompass all types of "inappropriate" customer behaviors that violate norms in exchange settings. However, abstraction level of dysfunctional behavior construct indicates that it appears to be a second-order or superordinate construct and it should be disaggregated by dimensions as sub-constructs (Bagozzi and Edwards, 1998; Edwards, 2001). Parasuraman and colleagues (1985)'s Service Quality construct is also a wellstudied umbrella construct (Babakus and Boller, 1992), which combine and operationalize (SERVQUAL) five interrelated 
sub-constructs (tangibility, reliability, responsiveness, assurance and empathy) that indicate customers' overall subjective quality perceptions about the service delivery process. It is almost impossible to argue that their conceptualization explains a single distinct service quality phenomenon; rather it provides a diverse set of phenomena that have something in common. As previously mentioned, after phenomena start to appear, scholars tend to define them broadly and extend the scope of their definitions. Later on, they are challenged with validity criticisms and they either evolve into a more valid form in time or lose their significance (Hirsch and Levin, 1999). As a healthy consequence of broad construct definition of Service Quality, several revised conceptualizations, adaptations, refinements and alternative scales have been introduced for almost three decades (Parasuraman et al., 1991; Cronin and Taylor, 1992; Dabholkar et al., 1996; Parasuraman et al., 2005; Brady et al., 2002). Service Quality and its measures were challenged with validity problems and gained more valid forms in time. They were revised and refined (Parasuraman et al., 1991), alternative measures were suggested (e.g. SERVPERF of Cronin and Taylor, 1992). They were adapted to different sectors and service environments (Dabholkar et al., 1992; Parasuraman et al., 2005). At this point, Hirsch and Levin (1999) argue that if a construct can tidy up its major elements, it becomes clearer and overcomes validity crisis. In this process, service quality has gained a more valid form and dimensional characteristics have been uncovered. We argue Brady and Cronin Jr. (2001)'s conceptual definition of Service Quality has more valid referring of single service quality phenomenon thus, in the next section; we will also discuss conceptualization of Service Quality as a bridging construct.

\subsection{Bridging Constructs}

Unlike umbrella constructs, bridging constructs refers to a single phenomenon. Bridging constructs are concepts, which integrate different elements, related to a single phenomenon (Floyd et al., 2011). Bridging constructs unify conceptually different elements and bridge the gap between separate set of literatures (Floyd et al., 2011). Bridging constructs are also suitable for connecting different theoretical elements or units of analyses, such as employees, customers, organizations, and institutions (Fuglsang and Jagd, 2015). For example, the field of dysfunctional behaviors needs bridging constructs to be introduced because these constructs synthesize different constructs under a single phenomenon and reconcile the paradox in the literature (Floyd et al., 2011; Poole and Van de Ven, 1989). There are few well-constructed bridging constructs in the literature because they create challenges for empirical analysis and theoretical explanations (Echambadi, Campbell, and Agarwal, 2006; Floyd et al., 2011). For instance, according to Floyd et al. ambidexterity is a good example of bridging construct, because it ties different elements (exploration and exploitation) and different trajectories (searching and learning). Service Quality conceptualization of Brady and Cronin Jr. (2001) also can be viewed as a bridging construct that ties different quality dimensions in service provision process. Different from previous second-order conceptualizations (such as SERVQUAL), they discover that previously accepted service quality constructs (such as reliability, empathy and responsiveness) are explained by three service dimensions (interaction, physical characteristics and outcome) and service quality ties these dimensions as a third-order latent construct.

\subsection{Specific Constructs}

Specific constructs are precise but contextually important phenomenon that can be represented by a small but concrete set of behavioral expressions. Specific constructs are fine-grained aspects of broader constructs (Bagozzi and Edwards, 1998), and have highly context-specific dispositions (Mowen and Voss, 2008). It is imperative to differentiate specific constructs and observable behavioral expressions. By definition, "constructs are not reducible to specific observations but, rather, are abstract statements of categories of observations" (Suddaby, 2010, p. 346). Therefore, directly or indirectly observable dark side behaviors cannot constitute a specific construct. Specific constructs are needed, at least, at one level of abstraction. "Shoplifting" (Babin and Babin, 1996) is a good example of specific constructs because shoplifting (1) is manifested by specific set of consumer behaviors, (2) is a very important problem for retail sectors (3) has one level of abstraction and represents an aspect of broader constructs, such as dysfunctional behaviors.

\subsection{Manifest Variables}

As previously explained, there are also direct observable behavioral manifestations or group of manifestations that have low level or no abstraction. These expressions are too specific to explain phenomena. These manifestations are directly observable and/or measurable entities, such as events, situations, behavioral expressions, perceptions or evaluations (Bagozzi, 2007; Schaffner, 1969). In this paper, we make a distinction between general manifestations and specific manifestations. General manifestations are the sets of highly correlated actions that cannot explain a phenomenon but can represent manifestations of real world phenomena. These sets of manifestations are reflective indicators, rather than formative (or composite) measures so indicators in a set of manifestations are highly correlated with other indicators and their higher-order construct. Specific manifestations are observable actions that have weak relations with other expressions. Specific manifestations are more suitable for formative measurement because a group of these expressions 
can be causal indicators that provide a composition for a construct (MacCallum and Browne, 1993). However, as argued in several previous studies, relationship between abstract (or latent) constructs and observable entities should be constructed reflectively, rather than formatively (Bagozzi, 2007, 2011; Howell, Breivik, and Wilcox, 2007; Jarvis et al., 2003).

In Table 1, characteristics and features of constructs are summarized.

Table 1: Characteristics of Construct Types

\begin{tabular}{|c|c|c|c|c|}
\hline Construct & Power & $\begin{array}{l}\text { Abstraction } \\
\text { Level }\end{array}$ & $\begin{array}{l}\text { Dimensional } \\
\text { Explanation }\end{array}$ & $\begin{array}{c}\text { Examples from Dysfunctional } \\
\text { Behavior Literature }\end{array}$ \\
\hline General Terms & $\begin{array}{c}\text { cannot } \\
\text { account for } \\
\text { any } \\
\text { phenomenon }\end{array}$ & $\begin{array}{l}\text { High level of } \\
\text { abstraction }\end{array}$ & Weak & Organizational Misbehavior \\
\hline $\begin{array}{l}\text { Umbrella } \\
\text { Constructs }\end{array}$ & $\begin{array}{l}\text { account for a } \\
\text { diverse set of } \\
\text { phenomena }\end{array}$ & $\begin{array}{l}\text { High level of } \\
\text { abstraction }\end{array}$ & $\begin{array}{c}\text { Weak/ } \\
\text { multidimensional }\end{array}$ & Dysfunctional behavior \\
\hline $\begin{array}{l}\text { Bridging } \\
\text { Constructs }\end{array}$ & $\begin{array}{l}\text { account for a } \\
\text { specific } \\
\text { phenomenon }\end{array}$ & $\begin{array}{l}\text { Moderate } \\
\text { level of } \\
\text { abstraction }\end{array}$ & $\begin{array}{c}\text { Strong/ } \\
\text { multidimensional }\end{array}$ & Workplace Aggression \\
\hline $\begin{array}{l}\text { Specific } \\
\text { Constructs }\end{array}$ & $\begin{array}{l}\text { account for a } \\
\text { specific } \\
\text { phenomenon }\end{array}$ & $\begin{array}{l}\text { Low level of } \\
\text { abstraction }\end{array}$ & $\begin{array}{c}\text { Strong/ } \\
\text { unidimensional }\end{array}$ & Fraudulent return \\
\hline $\begin{array}{l}\text { General } \\
\text { Manifestations }\end{array}$ & $\begin{array}{c}\text { cannot } \\
\text { account for } \\
\text { any } \\
\text { phenomenon }\end{array}$ & $\begin{array}{l}\text { Low level of } \\
\text { abstraction }\end{array}$ & $\begin{array}{c}\text { Weak/ } \\
\text { unidimensional }\end{array}$ & Ridiculing \\
\hline $\begin{array}{l}\text { Specific } \\
\text { Manifestations }\end{array}$ & $\begin{array}{l}\text { account for } \\
\text { any } \\
\text { phenomenon }\end{array}$ & $\begin{array}{c}\text { No } \\
\text { abstraction }\end{array}$ & $\begin{array}{c}\text { Weak/ } \\
\text { unidimensional }\end{array}$ & $\begin{array}{l}\text { Swearing in front of his/her } \\
\text { coworkers }\end{array}$ \\
\hline
\end{tabular}

Note: This figure is prepared by the authors

\section{DEFINING AND CLASSIFYING THE CONSTRUCTS IN THE FIELD OF DYSFUNCTIONAL BEHAVIOR: AN EXAMPLE}

Study areas that investigate negative, destructive, abnormal or dysfunctional behaviors in behavioral sciences (especially psychology, organizational behavior and marketing research) have suffered from construct proliferation and overlapping construct definitions for a long time. Bandura (1973) refers to these definitions in the abnormal psychology literature as semantic jungle. Nixon and Spector (2015) also define the field of workplace aggression as linguistic fog. Construct proliferation and using different labels for same phenomena are also one of the most stressed problems for defining customer misbehavior (Fisk et al., 2010; Greer, 2015). Thus, using the hierarchical approach proposed in this study for defining and classifying construct definitions in dysfunctional behavior fields provide clearer, more meaningful and less overlapping constructs that better fit the phenomena.

As the first step, authors scrutinize literature review articles and other published articles, which include construct definitions and classifications. Secondly, authors list all conceptual terms as well as scholar and lay definitions of these terms. Finally, scholar and lay definitions of the terms used in this literature are compared and dimensions, which are dominantly used for defining and dissociating them from other constructs, are determined.

\subsection{Defining the Field of Dysfunctional Behavior}

When defining the field, broadly defined general terms in organizational behavior and marketing literatures are determined: Organizational misbehavior, consumer misbehavior, aberrant behavior, problem behavior, deviant behavior and non-compliant behaviors. These terms have no clear dimensional explanation or indication for real world phenomena. From the consumer behavior perspective, consumer misbehavior and aberrant consumer behaviors are defined as "Behavioral acts by consumers which violate the generally accepted norms of conduct in consumption situations, and disrupt the order expected in such situations" (Fullerton and Punj, 1997, p. 336). Deviant behaviors are also defined as 
norm-violating harmful behaviors performed by organizational insiders or outsiders (Reynolds and Harris, 2006; Robinson and Bennett, 1995). These two definitions encompass all types of behaviors, which violate organizational or marketplace norms. However, norm-violation criterion is not comprehensive enough for demarcating the field because there are some negative and socially harmful behaviors that do not violate organizational or marketplace norms (Fowler III, 2007). Besides, there are also positive and constructive norm-violating behaviors (such as extra-role behaviors and some organizational citizenship behaviors) that violate the organizational norms but may have positive outcomes for organizational members, organization itself or society in general (Warren, 2003). It is argued that organizational misbehavior conceptualization of Ackroyd and Thompson provides well-fitted demarcation for these types of behaviors: "anything you do at work you are not supposed to do" $(1999$, p. 2). This definition has no dimensional explanation for these types of behaviors and no clear indication for a phenomenon so it cannot be labeled as a construct. On the other hand, it definitely has negative connotation and comprehensive limitation for negative and/or harmful behaviors. This definition encompasses not only deliberate harmful acts, which are the dominant subject matter of mainstream organization research, but also mistakes, accidents and errors, which are eschewed by mainstream works (Linstead et al., 2014).

\subsection{Determining Umbrella Constructs: Finding Elements in Common}

We determine two main conceptualizations that provide clear elements in common for a set of phenomena: "Dark side behavior" and "Dysfunctional behavior". Griffin and O'Leary-Kelley (2004) conceptualize dark side behavior as a "Motivated behavior by an employee or group of employees that has negative consequences for an individual within the organization, another group of individuals within the organization, or the organization itself". Griffin et al. (1998, p. 65) also define dysfunctional behavior as a "Motivated behavior by an employee or group of employees that has negative consequences for an individual within the organization, and/or the organization itself". Both terms delimitate constructs under them as motivated behaviors so these construct definitions eliminate unintentional mistakes or failures. It is important to note that there are some other construct definitions that delimit their construct as "voluntary" (see Robinson and Bennett (1995)'s deviant behavior definition), "intentional" (see Vardi and Weiner (1996)'s organizational misbehavior definition) or "deliberate" (see Harris and Reynolds (2004)'s jaycustomer behavior definition) acts. There are some arguments for and against using "intentionality" in the definitions of dysfunctional behaviors in literature. According to Neuman and Baron (2005), presence of perpetrator's intent is a prerequisite for defining aggressive events in organizations. According to them, if we eliminate the intent of the perpetrator, we assume some irrelevant cases as aggressive, such as dentists' or surgeons' unintentional harmful operational acts. According to Hershcovis and Barling (2007), on the other hand, if we assume all unintentional negative acts of employees or customers are beyond the scope of dysfunctional behaviors, we unnecessarily eliminate some specific cases or contexts that may have important contribution to the literature, such as alcoholic patients' violent and sexually abusive acts towards the nurses, which are prevalent today. In this study we prefer to delimitate dysfunctional behaviors as "motivated behaviors" (rather than intentional, voluntary or deliberate behaviors) since all of these types of behaviors are somewhat motivated, consciously or unconsciously. For instance, a dentist's or surgeon's harmful operation cannot be a dysfunctional or dark side behavior because it is not motivated by unconscious motives or conscious goals of the dentist or the surgeon. On the other hand, alcoholic patient's violence towards the nurses is clearly a dysfunctional behavior because it is motivated by alcohol and/or aggressive personality of the patient.

\subsection{Uncovering Bridging Constructs: Robust Connections among Subconstructs}

As previously explained, bridging constructs combine different ideas and dimensionally explain different elements related to a distinct phenomenon (Floyd et al., 2011). They also have the capacity to imply different levels and units of analyses (Floyd et al., 2011). However, it is hard to find well-defined bridging constructs in dysfunctional behavior studies. We believe that early conceptualization of "workplace aggression" by Baron and Neuman (1996), which is based on the classic typology of Buss (1961) qualify for a bridging construct. According to Baron and Neuman, there are eight types of aggressive behaviors that are performed for harming other organizational members and/or organization itself. These eight aggressive behavior types dissociate from others by three dichotomous dimensions: active/passive; direct/indirect and physical/nonphysical. For instance, 'employee violence' or 'customer violence' can be viewed as active, direct, physical (Neuman, 2004), 'employee service sabotage' (Harris and Ogbonna, 2002) can be viewed as active, indirect, nonphysical form and 'incivility' can be viewed as passive, indirect, nonphysical forms of workplace aggression. However, in time, empirical findings have not fully supported this typology and workplace aggression has turned into an umbrella construct that encompass all types of harmful acts within the organization (Hershcovis and Barling, 2007) and lost its connection with a specific phenomenon (intent to harm). 


\subsection{Specific Constructs in Dysfunctional Behavior Studies}

As previously explained, a specific construct has low level of abstraction and is highly connected to specific observables actions. It can also be connected to contextually relevant and important phenomena. For instance, customers' fraudulent return, which refers "consumers taking back goods to a retailer knowing that such a return is contrary to the firm's or legal rules and regulations" (Harris, 2008, p. 461), is a severe, prevalent and harmful phenomenon for retail environment. Fraudulent return encompasses very specific deliberately performed dysfunctional actions of consumers, which are backed by opportunistic motivations. This construct is directly manifested by a few types of behaviors (or instance, "getting refund for products that consumer have used or broken" see Harris (2008)'s scale). It is meaningless to relate this behavior to any type of workplace aggression because dominant motivation behind fraudulent return behavior is "intent to benefit self", rather than "intent to harm" so it is closely related to opportunistic forms of dysfunctional behaviors, such as opportunistic customer complaints, shoplifting and cheating behaviors.

\subsection{Manifest Variables and Suggestions for the Operationalization of Dysfunctional Behaviors}

In the field of dysfunctional behavior, there is a multitude of manifest variables that can be observed in workplace and marketplace environments, such as yelling, swearing, kicking, making sexual jokes, eye rolling and ignoring. These variables have almost no abstraction and have no potential to explain a phenomenon but they serve as scale items for several differently labelled and conceptualized constructs (such as injustice, aggression, incivility) that use similar manifest variables as scale items. For instance, asking the frequency of "yelling" or "swearing" someone at work is used in aggression scales (Glomb and Liao, 2003), incivility scales (Guidroz et al., 2010), rage (Harris, 2013), and mistreatment scales (Wang et al., 2011). Operationalization is one of the main concern in the field of dysfunctional behavior. These manifest variables are used as scale items of formative dysfunctional behavior measures although they are generally disparate elements of misbehavior research (Herschcovis and Reich, 2013). Therefore, it can be argued that using weakly related specific manifest variables in operational definitions of higher order specific, bridging or umbrella constructs increase the clarity and validity problems in the field of dysfunctional behavior. Although analyzing operational definitions is not the primary concern of this paper, similar with Herscovis and Reich (2013), using reflective measures is suggested in this paper for more valid measurement of constructs.

\section{CONCLUSION}

Severity of construct proliferation problem in literature disconnects communication between the members of scientific community, damages theoretical development and fragments accumulated knowledge (Suddaby, 2010). It is important to uncover construct overlaps, confusions between research streams and relational network between constructs. In order to overcome these problems, as previously mentioned, it is imperative to provide analytical vocabulary that would enable differentiation and connect actions and structures (Poole and Van de Ven, 1989). Current paper suggests a hierarchical approach for defining and classifying constructs and implements its approach to the field of dysfunctional behaviors in organizations and marketplace. It may help to develop distinct and clear constructs that have specified relations with other constructs in the field.

As suggested by Moven and Voss (2008), a hierarchical approach can provide distinctiveness between constructs and order constructs in a specific field based on their abstraction level. In our suggested hierarchical procedure, researchers can also determine overlapping problems of a construct with other constructs and its explanatory power of a phenomenon. At this point, difference between umbrella and bridging constructs becomes crucial. These two types of constructs have different characteristics for explaining phenomena. As previously explained, umbrella constructs have high abstraction and broad scope that encompass multiple ideas and account for a diverse set of phenomena (Hirsch and Levin, 1999; Floyd et al., 2011). On the other hand, bridging constructs also combine multiple ideas and elements but these ideas and elements are related to a single phenomenon (Floyd et al., 2011). Bridging constructs account for a phenomenon with multidimensional explanations and associate different elements (or subconstructs) with these multidimensional explanations and typologies. We argue that one of the few bridging constructs in the field of dysfunctional behavior, which is workplace aggression conceptualization of Baron and Neuman (1996), has turned into an umbrella construct because scholars in the field have broadened the concept and thus it lost connection with its target phenomenon. As a consequence, authors determine wellfitted umbrella constructs and discuss potential bridging constructs for closing the gap among study fields, connecting research streams and synthesizing different elements related to a specific phenomenon. In our proposal, every level of the abstraction continuum has idiosyncratic characteristics and determining the level of the construct helps to define it clearly.

Finally, it is important to note that this study mainly focuses on the conceptual characteristics of construct definitions, rather than operational characteristics and scale development processes. On the other hand, successful operationalization processes need clear and well-specified conceptual definition and clarification processes. We believe that our approach can 
be useful if it is applied before the operationalization of constructs. By doing so, researchers may clarify the characteristics of a phenomenon, its relations with other social phenomena, and its actual and possible manifestations in practical world.

\section{REFERENCES}

Ackroyd, S., and Thompson, P. (1999). Organizational Misbehaviour: London: SAGE Publications.

Aquino, K., and Thau, S. (2009). Workplace victimization: Aggression from the target's perspective. Annual review of psychology, 60 (1), 717-741.

Babakus, E., and Boller, G. W. (1992). An empirical assessment of the SERVQUAL scale. Journal of Business research, 24(3), 253-268.

Babin, B. J., and Babin, L. A. (1996). Effects of moral cognitions and consumer emotions on shoplifting intentions. Psychology and Marketing, 13(8), 785-802.

Bacharach, S. B. (1989). Organizational Theories: Criteria Some for Evaluation What Theory Is Not: Data, Typologies, and Metaphors, Academy of Management Review, 14(4), 496-515.

Bagozzi, R. P. (2007) On the Meaning of Formative Measurement and How It Differs from Reflective Measurement: Comment on Howell, Breivik, and Wilcox. Psychological Methods, 12(2), 229-237.

Bagozzi, R. P. (2011). Measurement and Meaning in Information Systems and Organizational Research: Methodological and Philosophical Foundations", MIS Quarterly, 35(2), 261-292.

Bagozzi, R. P., and Edwards, J. R. (1998). A general approach for representing constructs in organizational research. Organizational research methods, 1(1), 45-87.

Bandura, A. (1973). Aggression: A Social Learning Analysis, Englewood Cliffs, NJ: Prentice Hall

Baron, R. A., and Neuman, J. H. (1996). Workplace violence and workplace aggression: Evidence on their relative frequency and potential causes. Aggressive behavior, 22(3), 161-173.

Brady, M. K., and Cronin Jr, J. J. (2001). Some new thoughts on conceptualizing perceived service quality: a hierarchical approach. Journal of marketing, 65(3), 34-49.

Brady, M. K., Cronin Jr, J. J., and Brand, R. R. (2002). Performance-only measurement of service quality: a replication and extension. Journal of business research, 55(1), 17-31.

Buss, A. H. (1961). The Psychology of Aggression, New York: Wiley.

Churchill, G. A. (1979). A Paradigm for Developing Better Measures of Marketing Constructs. Journal of Marketing Research, 16(1), 64-73.

Cole, M. S., Walter, F., Bedeian, A. G., and O'Boyle, E. H. (2012). Job Burnout and Employee Engagement: A Meta-Analytic Examination of Construct Proliferation. Journal of Management, 38(5), 1550-1581.

Cronin Jr, J. J., and Taylor, S. A. (1992) Measuring service quality: a reexamination and extension, The Journal of Marketing, 56 (3), $55-68$.

Dabholkar, P. A., Thorpe, D. I., and Rentz, J. O. (1996). A measure of service quality for retail stores: scale development and validation. Journal of the Academy of Marketing Science, 24(1), 3-16.

DiRenzo, G. J. (1966). Concepts, theory and explanation in the behavioral sciences. New York: Random House.

Echambadi, R., Campbell, B., and Agarwal, R. (2006). Encouraging Best Practice in Quantitative Management Research: An Incomplete List of Opportunities. Journal of Management Studies, 43(8), 1801-1820.

Edwards, J. R. (2001). Multidimensional Constructs in Organizational Behavior Research: An Integrative Analytical Framework. Organizational Research Methods, 4(2), 144-192.

Edwards, J. R., and Bagozzi, R. P. (2000). On the Nature and Direction of Relationships Between Constructs and Measures. Psychological Methods, 5(2), 155-174

Fisk, R., Grove, S., Harris, L. C., Keeffe, D. A., Daunt, K. L., Russell-Bennett, R., and Wirtz, J. (2010). Customers behaving badly: a state of the art review, research agenda and implications for practitioners. Journal of Services Marketing, 24(6), 417-429.

Floyd, S. W., Cornelissen, J. P., Wright, M., and Delios, A. (2011). Processes and practices of strategizing and organizing: Review, development, and the role of bridging and umbrella constructs. Journal of Management Studies, 48(5), 933-952.

Fowler III, A. R. (2007). Hooligan's Holiday: Rethinking Deviant Consumer Behavior and Marketing. In G. Fitzsimons and V. Morvitz (Eds.), ACR North American Advances in Consumer Research, 34, 45-46. Duluth. 
Fuglsang, L., and Jagd, S. (2015). Making sense of institutional trust in organizations: Bridging institutional context and trust. Organization, 22(1), 23-39.

Fullerton, R. A., and Punj, G. (1997). Can Consumer Misbehavior Be Controlled? A Critical Analysis of Two Major Control Techniques. Advances in Consumer Research, 24, 340-344.

Fullerton, R. A., and Punj, G. (2004). Repercussions of promoting an ideology of consumption: Consumer misbehavior. Journal of Business Research, 57(11), 1239-1249.

Gerring, J. (2001). Social science methodology: A criterial framework. Cambridge: Cambridge University Press.

Gilliam, D. A., and Voss, K. (2013). A proposed procedure for construct definition in marketing. European Journal of Marketing, 47(1/2), 526.

Glomb, T. M., and Liao, H. (2003). Interpersonal aggression in work groups: Social influence, reciprocal, and individual effects. Academy of Management Journal, 46(4), 486-496.

Goertz, G. (2009). Social Science Concepts: A User's Guide. Princeton: Princeton University Press.

Greer, D. A. (2015). Defective co-creation: Developing a typology of consumer dysfunction in professional services. European Journal of Marketing, 49(1/2), 238-261.

Griffin, R. W., O'Leary-Kelly, A., and Collins, J. (1998). Dysfunctional work behavior in organizations. Journal of Organizational Behavior: Trends in Organizational Behavior, 5, 65-82

Griffin, R. W., and O'Leary-Kelly, A. M. (2004). "An Introduction to the Dark Side”, In R. W. Griffin and A. M. O'Leary-Kelly (Eds.), The Dark Side of Organizational Behavior, 1-19, San Francisco: Jossey-Bass.

Guidroz, A. M., Burnfield-Geimer, J. L., Clark, O., Schwetschenau, H. M., and Jex, S. M. (2010) The nursing incivility scale: Development and validation of an occupation-specific measure. Journal of Nursing Measurement, 18(3), 176.

Harris, L. C. (2008). Fraudulent Return Proclivity: An Empirical Analysis. Journal of Retailing, 84(4), 461-476.

Harris, L. C. (2013). Service employees and customer phone rage: An empirical analysis. European Journal of Marketing, 47(3/4), 463-484.

Harris, L. C., and Ogbonna, E. (2002). Exploring service sabotage: The antecedents, types and consequences of frontline, deviant, antiservice behaviors. Journal of Service Research, 4(3), 163-183.

Harris, L. C., and Reynolds, K. L. (2003). The consequences of dysfunctional customer behavior, Journal of Service Research, 6(2), $144-161$.

Harris, L. C., and Reynolds, K. L. (2004). Jaycustomer behavior: an exploration of types and motives in the hospitality industry. Journal of Services Marketing, 18(5), 339-357.

Hershcovis, M. S. (2011). 'Incivility, social undermining, bullying. . .oh my!': A call to reconcile constructs within workplace aggression research. Journal of Organizational Behavior, 32(3), 499-519.

Hershcovis MS, and Barling J. (2007). A relational perspective on workplace aggression: an examination of perpetrators and targets. In Dysfunctional Workplace: Management Challenges and Symptoms, In J Langan-Fox, CL Cooper and R Klimoski (eds.), 268-84. Cheltenham, UK: Elgar

Hershcovis, M. S., and Reich, T. C. (2013). Integrating workplace aggression research: Relational, contextual, and method considerations. Journal of Organizational Behavior, 34. S26-S42

Hirsch, P. M., and Levin, D. Z. (1999). Umbrella Advocates Versus Validity Police: A Life-Cycle Model, Organization Science, 10(2), $199-212$.

Howell, R. D., Breivik, E., and Wilcox, J. B. (2007). Reconsidering Formative Measurement, Psychological Methods, 12(2), 205-218.

Hunt, S. D. (1976). The Nature and Scope of Marketing, Journal of Marketing, 40(July 1976), 17-28.

Jarvis, C. B., MacKenzie, S. B., and Podsakoff, P. M. (2003). A Critical Review of Construct Indicators and Measurement Model Misspecification in Marketing and Consumer Research, Journal of Consumer Research, 30(2), 199-218.

Linstead, S., Maréchal, G., and Griffin, R. W. (2014). Theorizing and researching the dark side of organization, Organization Studies, 35(2), 165-188.

Locke, E. A. (2012). Construct validity vs. concept validity. Human Resource Management Review, 22(2), 146-148.

MacCallum, R. C., and Browne, M. W. (1993). The use of causal indicators in covariance structure models: some practical issues, Psychological Bulletin, 114(3), 533-541.

MacCorquodale, K., and Meehl, P. E. (1948). On a distinction between hypothetical constructs and intervening variables. Psychological Review, 55(2), 95-107. 
MacKenzie, S. B. (2003). The Dangers of Poor Construct Conceptualization. Journal of the Academy of Marketing Science, 31(3), $323-326$.

Markus, K. A. (2008). Constructs, Concepts and the Worlds of Possibility: Connecting the Measurement, Manipulation, and Meaning of Variables. Measurement: Interdisciplinary Research and Perspective, 6(1-2), 54-77.

Mowen, J. C., and Voss, K. (2008). On Building Better Construct Measures: Implications of a General Hierarchical Model. Psychology and Marketing, 25(6), 485-505.

Neuman, J. H. (2004). Injustice, stress, and aggression in organizations. In Griffin, R. W. and O'LearyKelly, A. M. (Eds), The Dark Side of Organizational Behavior. San Francisco, CA: Jossey-Bass

Neuman, J. H., and Baron, R. A. (2005). Aggression in the Workplace: A social-psychological Perspective, In Counterproductive Work Behavior: Investigations of actors and targets. 13-40, Washington DC: American Psychological Association.

Nixon, A. E., and Spector, P. E. (2015). Seeking Clarity in a Linguistic Fog: Moderators of the Workplace Aggression-Strain Relationship, Human Performance, 28(2), 137-164.

Osigweh, C. A. B. (1989). Concept Fallibility in Organizational Science. Academy of Management Review, 14(4), 579-594.

Parasuraman, A., Berry, L. L., and Zeithaml, V. A. (1991). Refinement and Reassessment of the SERVQUAL Scale. Journal of Retailing, 64, 1240.

Parasuraman, A., Zeithaml, V. A., and Berry, L. L. (1985). A Conceptual Model of Service Quality and Its Implications for Future Research. Journal of Marketing, 49(4), 41-50.

Parasuraman, A., Zeithaml, V. A., and Malhotra, A. (2005). ES-QUAL: A multiple-item scale for assessing electronic service quality. Journal of Service Research, 7(3), 213-233.

Podsakoff, P. M., Mackenzie, S. B., and Podsakoff, N. P. (2016). Recommendations for Creating Better Concept Definitions in the Organizational, Behavioral, and Social Sciences. Organizational Research Methods, 19(2), 1-45.

Poole, M. S., and Van de Ven, A. H. (1989). "Using Paradox to Build Management and Organization Theories", Academy of Management Review, 14(4), 562-578.

Reynolds, K. L., and Harris, L. C. (2006). Deviant Customer Behavior: An Exploration of Frontline Employee Tactics, The Journal of Marketing Theory and Practice, 14(2), 95-111.

Reynolds, K. L., and Harris, L. C. (2009). Dysfunctional Customer Behavior Severity: An Empirical Examination. Journal of Retailing, 85(3), 321-335.

Robinson, S. L., and Bennett, R. J. (1995). A Typology of Deviant Workplace Behaviors: A Multidimensional Scaling Study. Academy of Management Journal, 38(2), 555-572.

Rossiter, J. R. (2011). Measurement for the social sciences: The C-OAR-SE method and why it must replace psychometrics. New York, NY: Springer Science + Business Media

Schaffner, K. F. (1969). Correspondence Rules. Philosophy of Science, 36(3), 280-290.

Shapiro, D. L., Duffy, M. K., Kim, T.-Y., Lean, E. R., and O'Leary-Kelly, A. (2008). Rude," “Uncivil," or "Disrespectful” Treatment in the Workplace: What's in a Name. In Justice, Morality, and Social Responsibility, 227-262. IAP.

Singh, J., Brady, M., Arnold, T., and Brown, T. (2017). The Emergent Field of Organizational Frontlines. Journal of Service Research, 20(1), 311.

Suddaby, R. (2010). Editor's comments: Construct clarity in theories of management and organization. Academy of Management Review, 35(3), 346-357.

Tepper, B. J., and Henle, C. A. (2011). A case for recognizing distinctions among constructs that capture interpersonal mistreatment in work organizations. Journal of Organizational Behavior, 32(3), 487-498.

Vardi, Y., and Wiener, Y. (1996). Misbehavior in Organizations: A Motivational Framework. Organization Science, 7(2), $151-165$.

Wang, M., Liao, H., Zhan, Y., and Shi, J. (2011). Daily customer mistreatment and employee sabotage against customers: Examining emotion and resource perspectives. Academy of Management Journal, 54(2), 312-334.

Warren, D. E. (2003). Constructive and Destructive Deviance in Organizations", Academy of Management Review, 28(4), 622-632. 